\title{
The impact of generic-only drug benefits on patients' use of inhaled corticosteroids in a Medicare population with asthma Vicki Fung1, Ira B Tager ${ }^{2}$, Richard Brand ${ }^{3}$, Joseph P Newhouse ${ }^{4,5,6}$ and John Hsu*1
}

Address: ${ }^{1}$ Center for Health Policy Studies, Kaiser Permanente Division of Research, Oakland, California, USA, ${ }^{2}$ Division of Epidemiology, University of California, Berkeley, USA, ${ }^{3}$ Department of Epidemiology and Biostatistics, University of California, San Francisco, USA, ${ }^{4}$ Department of Health Care Policy, Harvard Medical School, Boston, Massachusetts, USA, ${ }^{5}$ Department of Health Policy and Management, Harvard School of Public Health, Boston, Massachusetts, USA and ${ }^{6}$ Kennedy School of Government, Harvard University, Cambridge, Massachusetts, USA

Email: Vicki Fung - Vicki.Fung@kp.org; Ira B Tager - ibt@berkeley.edu; Richard Brand - rjbrand@sbcglobal.net; Joseph P Newhouse - newhouse@hcp.med.harvard.edu; John Hsu* - jth@dor.kaiser.org

* Corresponding author

Published: 18 July 2008

BMC Health Services Research 2008, 8:15I doi:10.1 I86/1472-6963-8-15।
Received: 4 December 2007

Accepted: 18 July 2008

This article is available from: http://www.biomedcentral.com/I472-6963/8/I5 I

(C) 2008 Fung et al; licensee BioMed Central Ltd.

This is an Open Access article distributed under the terms of the Creative Commons Attribution License (http://creativecommons.org/licenses/by/2.0), which permits unrestricted use, distribution, and reproduction in any medium, provided the original work is properly cited.

\begin{abstract}
Background: Patients face increasing insurance restrictions on prescription drugs, including generic-only coverage. There are no generic inhaled corticosteroids (ICS), which are a mainstay of asthma therapy, and patients pay the full price for these drugs under generic-only policies. We examined changes in ICS use following the introduction of generic-only coverage in a Medicare Advantage population from 2003-2004.

Methods: Subjects were age 65+, with asthma, prior ICS use, and no chronic obstructive pulmonary disorder $(n=1,802)$. In $2004,74.0 \%$ switched from having a $\$ 30$ brand-copayment plan to a generic-only coverage plan (restricted coverage); $26 \%$ had \$15-25 brand copayments in 2003-2004 (unrestricted coverage). Using linear difference-in-difference models, we examined annual changes in ICS use (measured by days-of-supply dispensed). There was a lower-cost ICS available within the study setting and we also examined changes in drug choice (higher- vs. lower-cost ICS). In multivariable models we adjusted for socio-demographic, clinical, and asthma characteristics.

Results: In 2003 subjects had an average of I 88 days of ICS supply. Restricted compared with unrestricted coverage was associated with reductions in ICS use from 2003-2004 (- 15.5 days-of-supply, $95 \%$ confidence interval (Cl): -25.0 to -6.0$)$. Among patients using higher-cost ICS drugs in $2003(n=662)$, more restricted versus unrestricted coverage subjects switched to the lower-cost ICS in 2004 (39.8\% vs. 10.3\%). Restricted coverage was not associated with decreased ICS use (2003-2004) among patients who switched to the lower-cost ICS (I8.7 days-of-supply, Cl: -27.5 to 65.0), but was among patients who did not switch (-38.6 days-of-supply, $\mathrm{Cl}$ : -57.0 to -20.3$)$. In addition, restricted coverage was associated with decreases in ICS use among patients with both higher- and lower-risk asthma (-I5.0 days-of-supply, Cl: $4 \mathrm{I} .4$ to II.44; and - 15.6 days-of-supply, Cl: -25.8 to -5.3 , respectively).

Conclusion: In this elderly population, patients reduced their already low ICS use in response to losing drug coverage. Switching to the lower-cost ICS mitigated reductions in use among patients who previously used higher-cost drugs. Additional work is needed to assess barriers to switching ICS drugs and the clinical effects of these drug use changes.
\end{abstract}




\section{Background}

As prescription drug costs continue to rise, public and private payers are increasing insurance restrictions and patient cost-sharing for prescription drugs. Cost-sharing aims to promote cost-effective drug consumption, such as greater use of generic drugs or reduced use of clinically unnecessary drugs, by exposing patients to a greater share of the costs of treatment. For example, in the United States, Medicare Part D drug benefits, which were offered starting in 2006 through a number of private plans, include high levels of cost-sharing. In 2007, about $70 \%$ of Part D drug plans included a coverage gap (often referred to as a "doughnut hole") wherein patients lose coverage for all drugs after their total drug spending exceeds $\$ 2,400$ and until their out-of-pocket costs reach $\$ 3,850$. About $27 \%$ of plans supplement this coverage gap with genericonly coverage, under which patients have coverage for generic drugs, but no coverage for brand-name drugs [1].

Under Medicare Part D cost-sharing arrangements, many beneficiaries may be at risk for losing drug coverage for inhaled corticosteroids (ICS) during the coverage gap, even if they have generic-only coverage supplements, because no generic ICS formulations are available in the U.S. Inhaled corticosteroids are the mainstay of treatment for all forms of asthma, except mild-intermittent [2] and asthma affects approximately seven percent of Americans age 65 years and older [3]. Other medications used similarly to control asthma symptoms, such as bronchodilators and theophyllines, have inferior efficacy and/or safety profiles compared with inhaled corticosteroids $[2,4,5]$. ICS use is associated with lower rates of emergency department (ED) visits, asthma-related hospitalizations, and mortality $[4,6,7]$.

To gain insight about the impact of brand name drug coverage loss, we examined changes in ICS use among Medicare Advantage (MA) beneficiaries whose plans switched from generic and brand coverage with an annual cap in 2003 to generic-only coverage (i.e., no ICS coverage) in 2004. We compared them with MA enrollees with brandname coverage in both 2003 and 2004.

\section{Methods \\ Setting}

We used automated data from Kaiser Permanente-Northern California (KPNC), an integrated delivery system that provides comprehensive medical care to over three million members, which included about 280,000 MA beneficiaries. Members could join the KPNC MA plan either by purchasing individual insurance or through plans supplemented by their current or former employers. There was only one MA plan (i.e., single cost-sharing structure) for individual subscribers, while employers determined KPNC cost-sharing levels for patients with employer-supplemented plans.

In 2003 individual MA beneficiaries had $\$ 10$ generic and $\$ 30$ brand copayments, and a $\$ 1,000$ benefit cap (meaning they paid full member price for drugs after their total drug expenditures exceeded $\$ 1,000$ during the year). In 2004 , the cap was replaced with generic-only coverage i.e., patients paid full member price for brand drugs, and $\$ 10$ copayments for generics throughout the year ("restricted coverage"). By contrast, employer-supplemented MA beneficiaries paid \$10 generic and \$15-25 brand copayments 2003-2004, with no other limits ("unrestricted coverage"). Patients' coverage type was determined by their employment history and enrollees could not switch between the coverage types (please see Table 1).

The full member price includes the drug acquisition and dispensing costs and reflects discounts obtained by the health system; it is generally lower than local retail prices. During the study period, KPNC offered one ICS brand, beclomethasone dipropionate (Qvar), at a significantly lower member price compared with other inhaled corticosteroids. Beclomethasone dipropionate was the most frequently prescribed ICS within the health system, comprising $75 \%$ of all ICS prescriptions in our study, and was followed by fluticasone propionate (Flovent), which comprised $23 \%$ of ICS prescriptions (i.e., $92 \%$ of non-beclomethasone dipropionate prescriptions). The average cost increase due to loss of coverage for a canister of beclomethasone dipropionate was about $\$ 15$, compared with $\$ 65$ or $\$ 110$ for fluticasone propionate $110 \mathrm{mcg}$ or 220

Table I: Summary of drug benefits 2003-2004: unrestricted and restricted coverage groups

\begin{tabular}{lcc}
\hline Coverage group & 2003 & 2004 \\
\hline Unrestricted Coverage & $\$ 10$ generic copayment & $\$ 10$ generic copayment \\
& $\$ 15-25$ brand copayment & $\$ 15-25$ brand copayment \\
Restricted Coverage & $\$ 10$ generic copayment & $\$ 10$ generic copayment \\
& $\$ 30$ brand copayment & No brand coverage (i.e., full-price for brands) \\
& No annual drug benefit cap
\end{tabular}


mcg, respectively. The KPNC Institutional Review Board approved the study.

\section{Study population}

All subjects included in this study $(\mathrm{N}=1,802)$ were continuous MA enrollees (January 1, 2003-December 31, 2004), 65+ years old, who met at least one of the following criteria as of January 1, 2003: (1) $\geq 1$ inpatient admissions with a primary asthma diagnosis in the previous three years; (2) $\geq 1$ ED visits with an asthma diagnosis in the previous two years; or (3) $\geq 2$ outpatient visits with an asthma diagnosis in the previous two years. Further, all subjects were dispensed $\geq 30$ days-of-supply of an ICS in both 2002 and 2003. We excluded patients with inpatient or outpatient chronic obstructive pulmonary disorder (COPD) diagnoses: ICD-9-CM codes 491 (chronic bronchitis), 492 (emphysema), 493.20 (asthma with COPD), or 496 (COPD) in 2003-2004. We also excluded patients who were dispensed ipratropium bromide (Atrovent), the primary pharmacologic therapy for COPD within KPNC in 2003 or 2004, and patients with Medicaid because they had substantially lower cost-sharing.

\section{Levels and type of ICS use}

We measured ICS use based on days-of-supply dispensed. Days-of-supply were calculated for each prescription by multiplying the number of actuations per canister by the number of canisters dispensed and dividing by the prescribed dose (actuations) and frequency of administration. We carried over remaining supply from month-tomonth and calculated patients' ICS supply in each month (standardized to a 30-day month) and year. We considered beclomethasone dipropionate as "lower-cost", and all other ICS brands as "higher-cost". We calculated monthly and annual days-of-supply for lower- and higher-cost ICS drugs separately. We also classified patients as either lower- or higher-cost ICS users in each year by the type with the greater days-of-supply.

\section{Covariates}

Comparisons between the restricted and unrestricted coverage groups were adjusted for a number of potential confounders including age, gender, and race/ethnicity. Race/ ethnicity was determined based on routine member surveys and inpatient records (we included an unknown category with $7.5 \%$ of subjects). We constructed a neighborhood socioeconomic status (SES) indicator using patients' residential addresses and information from the 2000 US Census. Neighborhoods were considered low SES if $\geq 20$ percent of residents had average household incomes below the federal poverty level, or $\geq$ 25 percent of residents $\geq 25$ years old had less than a high school education $[8,9]$. We adjusted for comorbidity based on the prospective diagnostic cost group (DxCG) score, which is similar to the risk-adjustment method used by the Centers for Medicare and Medicaid Services [10], and included indicators for coronary artery disease, diabetes, heart failure, and hypertension based on membership in the health system's chronic disease registries.

To adjust for asthma severity, we used a number of medication- and diagnosis-related variables in 2002: number of rescue medication canisters dispensed, having a highdose ICS, any oral steroid dispensed, a high-risk asthma registry flag (see Table 2 footnote for criteria), and any asthma-related ED visits or hospitalizations. We also adjusted for ICS days-of-supply in 2003. We determined the high-dose thresholds based on the Global Initiative for Asthma treatment guidelines [2].

\section{Analyses}

To adjust for potential confounders, we represented the covariates via a propensity score [11]. For each subject we calculated their probability of having generic-only coverage in 2004 with a logistic model that included all of the covariates described above. Based on these predicted probabilities, we classified patients into propensity score quintiles [12]. We confirmed that covariate distributions were comparable across coverage groups within each quintile and found no statistically significant differences using Pearson chi-square tests for categorical variables and t-tests for continuous variables. As a sensitivity test, we compared propensity score with traditional covariate adjustment; point estimates and standard errors were similar across the methods.

To examine monthly ICS use we used a linear model and estimated coefficients using a generalized estimating equation (GEE) approach. The models included indicators for propensity score quintile (2-5), month (2-24), restricted coverage, and interactions between restricted coverage and month. The coefficients of the interactions test the hypothesis that coverage type was associated with different patterns of ICS use over months.

To examine changes in annual ICS use associated with restricted coverage we calculated the change in days-ofsupply (2004 minus 2003) for each subject and used this difference as the outcome in linear models, adjusted for propensity score quintile. We examined annual changes among all subjects, among users of higher- and lower-cost ICSs in 2003, separately, and by type of ICS use in 2004, separately. We also examined changes in ICS use among patients identified as having high-risk asthma in the health system's disease registry, and those with lower-risk asthma (i.e., no high-risk flag).

Lastly, we examined the patient characteristics associated with having no ICS use in 2004 using multivariable logis- 
Table 2: Study population: patient characteristics

\begin{tabular}{|c|c|c|c|c|c|}
\hline \multirow[b]{2}{*}{ Characteristic } & \multirow[t]{2}{*}{ Total } & \multicolumn{2}{|c|}{ Unrestricted Coverage } & \multicolumn{2}{|c|}{ Restricted Coverage } \\
\hline & & $\begin{array}{r}\text { Lower-cost ICS User in } \\
2003\end{array}$ & $\begin{array}{r}\text { Higher-cost ICS User in } \\
2003\end{array}$ & $\begin{array}{r}\text { Lower-cost ICS User in } \\
2003\end{array}$ & $\begin{array}{r}\text { Higher-cost ICS User in } \\
2003\end{array}$ \\
\hline No. subjects & 1,802 & 293 & 175 & 847 & 487 \\
\hline Female* & $67.7 \%$ & $63.8 \%$ & $65.7 \%$ & $68.8 \%$ & $68.8 \%$ \\
\hline Age: $65-74$ & $63.5 \%$ & $60.4 \%$ & $57.7 \%$ & $62.6 \%$ & $69.2 \%$ \\
\hline $75-84$ & $31.4 \%$ & $33.8 \%$ & $38.9 \%$ & $31.6 \%$ & $26.7 \%$ \\
\hline $85+$ & $5.1 \%$ & $5.8 \%$ & $3.4 \%$ & $5.8 \%$ & $4.1 \%$ \\
\hline Race/ethnicity*: White & $68.1 \%$ & $71.0 \%$ & $70.3 \%$ & $67.1 \%$ & $67.4 \%$ \\
\hline Black & $4.4 \%$ & $7.2 \%$ & $6.3 \%$ & $2.8 \%$ & $4.9 \%$ \\
\hline Hispanic & $6.9 \%$ & $3.1 \%$ & $2.9 \%$ & $8.5 \%$ & $8.0 \%$ \\
\hline Asian & $10.8 \%$ & $10.6 \%$ & $12.6 \%$ & $10.5 \%$ & $10.9 \%$ \\
\hline Other & $3.2 \%$ & $3.8 \%$ & $3.4 \%$ & $3.1 \%$ & $3.1 \%$ \\
\hline Unknown & $6.5 \%$ & $4.4 \%$ & $4.6 \%$ & $8.0 \%$ & $5.8 \%$ \\
\hline $\begin{array}{l}\text { Neighborhood SES*: } \\
\text { Non-low }\end{array}$ & $80.4 \%$ & $84.0 \%$ & $83.4 \%$ & $78.3 \%$ & $80.9 \%$ \\
\hline Low & $17.7 \%$ & $14.3 \%$ & $14.9 \%$ & $19.5 \%$ & $17.7 \%$ \\
\hline Unknown & $1.9 \%$ & $1.7 \%$ & $1.7 \%$ & $2.2 \%$ & $1.4 \%$ \\
\hline Coronary Artery Disease & $10.9 \%$ & $11.3 \%$ & $12.6 \%$ & $10.6 \%$ & $10.5 \%$ \\
\hline Diabetes & $15.5 \%$ & $14.0 \%$ & $15.4 \%$ & $15.9 \%$ & $15.6 \%$ \\
\hline Heart Failure* & $5.7 \%$ & $8.2 \%$ & $6.9 \%$ & $5.4 \%$ & $4.1 \%$ \\
\hline Hypertension & $55.9 \%$ & $61.8 \%$ & $55.4 \%$ & $56.9 \%$ & $50.7 \%$ \\
\hline \multirow[t]{2}{*}{$\begin{array}{l}\text { Exceeded } \$ 1,000 \text { drug } \\
\text { cap in } 2003\end{array}$} & -- & -- & -- & $21.3 \%$ & $44.2 \%$ \\
\hline & Mean (SD) & Mean (SD) & Mean (SD) & Mean (SD) & Mean (SD) \\
\hline $\begin{array}{l}\text { Comorbidity (DxCG) } \\
\text { score* }\end{array}$ & $0.94(0.57)$ & $1.00(0.65)$ & $1.02(0.60)$ & $0.94(0.57)$ & $0.89(0.5 \mathrm{I})$ \\
\hline
\end{tabular}

Notes: Lower-cost ICS Users in 2003 defined as patients with greater use of lower-cost than higher-cost ICS drugs in 2003. The 2003 diagnostic cost group (DxCG) score was calculated based on prior year diagnoses and procedures [DxCG Inc., Waltham, MA]. The range for the DxCG score was 0.24 to 5.48 , median $=0.79$

$* \mathrm{p}<.05$ for difference between unrestricted and restricted coverage

tic regression, and included the covariates described above.

\section{Results}

\section{Patient characteristics}

Table 2 displays the characteristics of the 1,802 study subjects: 1,334 subjects (74\%) had restricted, and 468 (26.0\%) had unrestricted coverage. As shown in Table 3, higher-cost ICS users in 2003 were more likely to have high-risk asthma, prior oral steroid use, and a high ICS dose level, compared with lower-cost ICS users. In 2003, the average ICS days-of-supply dispensed was 187.5 (supply for $51.4 \%$ of days). In 2004 , use decreased for all groups; overall, patients had an average of 161.3 days-ofsupply (supply for $44.2 \%$ of days).

\section{Monthly ICS use}

Figure 1 presents monthly ICS use separately for lowerand higher-cost ICS users with restricted and unrestricted coverage. Among lower-cost ICS users in 2003, there was little difference in ICS use between the coverage groups throughout the study period. Among higher-cost ICS users in 2003, restricted coverage patients decreased their ICS use relative to unrestricted coverage patients toward the end of 2003, as an increasing number of restricted coverage subjects exceeded the $\$ 1,000$ benefit cap (Table 2), and these differences remained in 2004 after the loss of brand-name coverage.

\section{Changes in ICS type}

Figure 2 displays the distribution of the type of ICS use in 2004 (lower-cost versus higher-cost), by patients' type of ICS use in 2003 and coverage group. Overall, 13.9\% of subjects had no ICS use in 2004. Among higher-cost ICS users in 2003, $16.2 \%$ of restricted and $9.7 \%$ of unrestricted coverage patients had no ICS use in 2004 (p = 0.036 ). In addition, $39.8 \%$ of restricted versus $10.3 \%$ of unrestricted coverage patients switched to the lower-cost ICS in $2004(\mathrm{p}<.001)$. Among lower-cost ICS users in 2003, levels of non-use of ICS drugs in 2004 were similar for unrestricted and restricted coverage patients; switching to higher-cost ICS drugs was uncommon in both groups, but higher in the unrestricted coverage group $(4.1 \%$ versus $1.5 \%, \mathrm{p}=0.010$ ). 
Table 3: Study population: asthma characteristics

\begin{tabular}{|c|c|c|c|c|c|}
\hline \multirow[b]{2}{*}{ Characteristic } & \multirow[b]{2}{*}{ Total } & \multicolumn{2}{|c|}{ Unrestricted Coverage } & \multicolumn{2}{|c|}{ Restricted Coverage } \\
\hline & & $\begin{array}{r}\text { Lower-cost ICS User } \\
\text { in } 2003\end{array}$ & $\begin{array}{r}\text { Higher-cost ICS User } \\
\text { in } 2003\end{array}$ & $\begin{array}{r}\text { Lower-cost ICS User } \\
\text { in } 2003\end{array}$ & $\begin{array}{r}\text { Higher-cost ICS User } \\
\text { in } 2003\end{array}$ \\
\hline No. subjects & 1,802 & 293 & 175 & 847 & 487 \\
\hline High-risk asthma flag in $2002^{*}$ & $12.1 \%$ & $10.9 \%$ & $17.1 \%$ & $9.0 \%$ & $16.4 \%$ \\
\hline $\begin{array}{l}\text { ED visit or hospitalization for } \\
\text { asthma in } 2002\end{array}$ & $6.7 \%$ & $9.2 \%$ & $5.1 \%$ & $5.3 \%$ & $8.2 \%$ \\
\hline $\begin{array}{l}\text { Oral steroid Rx dispensed in } \\
2002\end{array}$ & $31.4 \%$ & $27.7 \%$ & $32.6 \%$ & $27.5 \%$ & $39.8 \%$ \\
\hline Low ICS dose level in 2002 & $31.4 \%$ & $55.3 \%$ & $10.9 \%$ & $53.5 \%$ & $14.0 \%$ \\
\hline $\begin{array}{l}\text { Medium ICS dose level in } \\
2002\end{array}$ & $36.2 \%$ & $36.5 \%$ & $37.1 \%$ & $36.6 \%$ & $35.1 \%$ \\
\hline \multirow[t]{2}{*}{ High ICS dose level in 2002} & $24.8 \%$ & $8.2 \%$ & $52.0 \%$ & $9.9 \%$ & $50.9 \%$ \\
\hline & Mean (SD) & Mean (SD) & Mean (SD) & Mean (SD) & Mean (SD) \\
\hline $\begin{array}{l}\text { No. of rescue medication } \\
\text { canisters dispensed in } 2002\end{array}$ & $3.73(4.79)$ & $3.57(4.80)$ & $4.06(5.10)$ & $3.44(4.12)$ & $4.18(5.64)$ \\
\hline ICS Days-of-supply in $2003 * *$ & $187.5(103.3)$ & $200.0(107.2)$ & $204.4(104.3)$ & $187.8(102.7)$ & I $73.4(99.9)$ \\
\hline ICS Days-of-supply in $2004^{* *}$ & $161.3(120.3)$ & 184.7 (I24.7) & $184.4(119.0)$ & $162.0(120.9)$ & $137.5(112.8)$ \\
\hline
\end{tabular}

Notes: Lower-cost ICS Users in 2003 defined as patients with greater use of lower-cost than higher-cost ICS drugs in 2003. ICS dose level categorized based on the first prescription in 2002 and the Global Initiative for Asthma treatment guidelines.

* The registry classified patients as high-risk if they met any of the following criteria: $(\mathrm{I}) \geq \mathrm{I}$ inpatient admissions with a primary asthma diagnosis in the previous 12 months, (2) $\geq 1$ inpatient admissions with a secondary asthma diagnosis in the previous 12 months, accompanied by a primary asthma-related diagnosis, (3) $\geq I$ ED visits with an asthma diagnosis in the previous six months, (4) $\geq 5$ prescriptions for asthma medication in the previous six months with $\geq 2$ oral steroid prescriptions in the previous 12 months, or $(5) \geq 12$ canisters of inhaled beta-agonists in the previous 12 months.

** $\mathrm{p}<.05$ for difference between unrestricted and restricted coverage groups

\section{Annual changes in ICS use}

Table 4 presents the associations between coverage type and changes in ICS use from 2003 to 2004, adjusted for covariables. Overall, restricted coverage patients reduced their ICS use by an average of 15.5 days-of-supply (95\% confidence interval (CI): -25.0 to -6.0 ) more than unrestricted coverage patients. Among lower-cost ICS users in 2003, restricted coverage was associated with a reduction of 12.8 days-of-supply (CI: -24.3 to -1.3 ); among highercost ICS users in 2003, restricted coverage was associated with a reduction of 21.8 days-of-supply (CI: -38.5 to -5.1 ).

For higher-cost ICS users in 2003, the effect of restricted coverage on ICS use differed by the type of medication used in 2004. Restricted coverage was not associated with decreased ICS use (2003-2004) among patients who switched to the lower-cost ICS in 2004 (18.7 days-of-supply, CI: -27.5 to 65.0$)$, but was among patients who did not switch (-38.6 days-of-supply, CI: -57.0 to -20.3$)$.

We also examined changes in ICS use associated with restricted coverage, stratified by asthma disease severity, as defined by having a high-risk asthma flag in the disease registry (Table 5). Table 5 also presents levels of ICS use in each group in 2003. As expected, baseline ICS use was greater among higher-risk asthma patients as compared with lower-risk within each of the coverage groups; how- ever, differences by severity level were relatively small among patients with coverage restrictions as compared with those without restrictions in either year (difference of 11.6 vs. 29.9 days-of-supply). In contrast, restricted coverage was associated with similar reductions in ICS use in the higher-risk (-15.0 days-of-supply, CI: -41.4 to 11.4 ) and lower-risk (-15.6 days-of-supply, CI: -25.8 to -5.3$)$ asthma groups.

\section{Characteristics associated with no ICS use in 2004}

In separate analyses (more details available upon request), among all subjects and among higher-cost ICS users in 2003, restricted coverage was not significantly associated with having no ICS use in 2004 (OR = 1.18, CI: 0.83-1.67; and OR = 1.65, CI: 0.89-3.04, respectively). Among all subjects, having a high-dose ICS in 2002 and greater ICS use (days-of-supply) in 2003 were associated with lower odds of no ICS use in 2004 (OR $=0.65, \mathrm{CI}$ : 0.46-0.92; and $\mathrm{OR}=0.89$, CI: 0.87-0.91, respectively).

\section{Discussion}

Inhaled corticosteroids are a critical component of therapy for persistent asthma. In this population of Medicare beneficiaries with asthma, levels of ICS use were low (as shown in Table 3): on average, patients had drug supply for only about half of the year in 2003. Moreover, loss of 

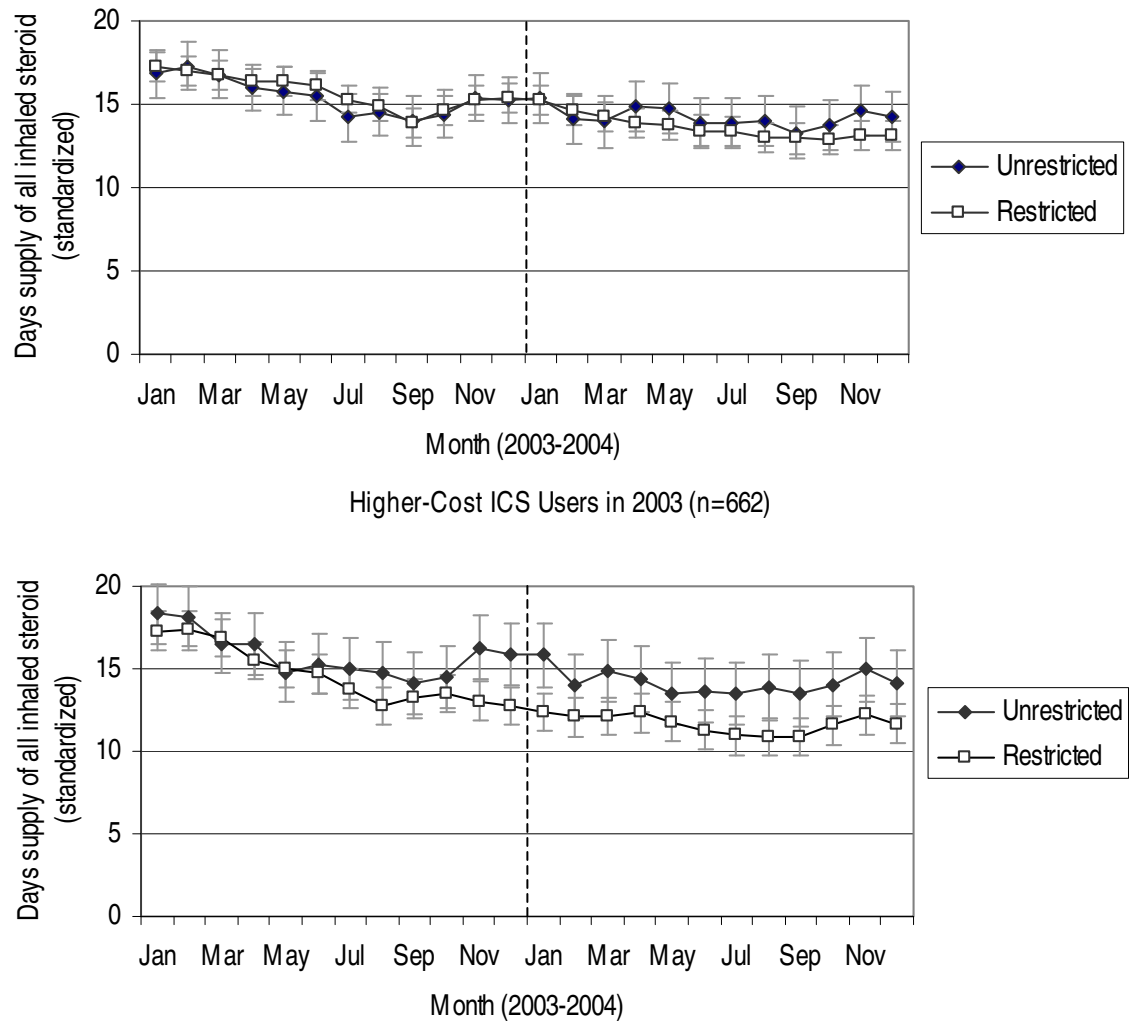

Figure I

Adjusted mean monthly ICS days-of-supply (2003-2004) for lower-cost and higher-cost ICS users in 2003 by coverage group. Note: The graph presents the adjusted mean monthly days-of-supply (standardized to a 30-day month) of all inhaled corticosteroids for the Unrestricted and Restricted Coverage groups. Bars represent $95 \%$ confidence intervals.

coverage for ICS drugs in 2004 was associated with reductions in ICS use.

Restricted drug coverage was associated with a modest reduction in ICS use even among patients who faced smaller increases in out-of-pocket costs because they were using the lower-cost ICS in 2003 before the loss of brandname coverage. Changes in ICS use from 2003 to 2004 were more pronounced among the one-third of patients who were prescribed higher-cost inhaled corticosteroids in 2003. As expected, a number of these patients with restricted coverage switched to the lower-cost drug in 2004 (about 40 percent), and switching appeared to mitigate reductions in 2004 ICS use due to loss of drug coverage. However, many patients did not switch to the lowercost ICS and those with restricted coverage reduced their ICS use by over one month of supply compared with patients with unrestricted coverage.
Patients who were taking higher-cost ICS drugs at baseline exhibited greater asthma severity compared with lowercost ICS users, as indicated by several medication and diagnoses measures shown in Table 3. In addition, in analyses stratified by asthma severity level (Table 5), loss of brand-name drug coverage was associated with reductions in ICS use, even among those with a strong clinical indication for the drug therapy (i.e., higher-risk asthma patients). Decreases in ICS use in the high-risk asthma group may reflect greater increases in drug costs associated with the loss of coverage, due to higher average daily doses. Alternatively, the high-risk asthma flag indicates a prior history of frequent or serious exacerbations, which may be associated with worse self-management of asthma symptoms. These findings raise important questions about potential adverse clinical consequences of reduced ICS use due to restrictive drug coverage policies, particularly for patients with greater clinical need for ICS therapy. Studies in non-elderly asthma populations have found that lower levels of ICS use are associated with greater hos- 


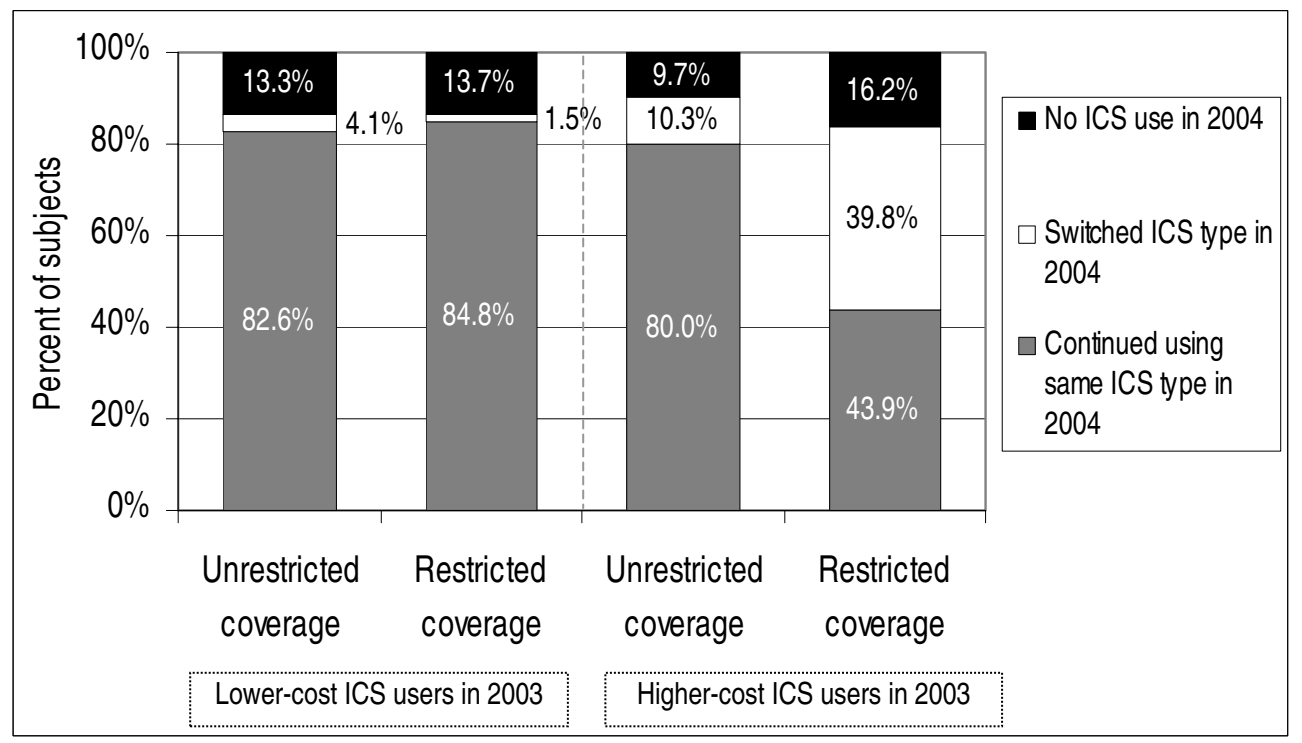

Figure 2

Type of ICS use in 2004 by coverage group and type of ICS use in 2003. Note: Lower-cost ICS Users in 2003 and 2004 were defined as patients with greater use of lower-cost than higher-cost ICS drugs in each year, and vice-versa. Patients were defined as having No ICS Use in 2004 if their total annual ICS days-of-supply was zero.

pitalizations, emergency department visits, and oral steroid use $[6,13,14]$. In addition, evidence suggests that increases in drug costs associated with ICS use are off-set by decreases in other direct medical costs [15-19]. Research is needed to assess clinical outcomes associated with these drug coverage policies, as well as to determine the impact on total medical costs.
Encouraging greater substitution of higher-cost with lower-cost ICS drugs could mitigate potential adverse effects of restricted drug coverage policies. In this setting, switching to the lower-cost ICS would not be likely to result in adverse clinical effects as head-to-head trials have not produced definitive conclusions on the comparative efficacy of different inhaled corticosteroids [5]. There is some evidence that suggests that potency, or the dose nec-

Table 4: Adjusted change in annual ICS days-of-supply for lower and higher-cost ICS users in 2003: restricted vs. unrestricted coverage

\begin{tabular}{|c|c|c|c|c|c|}
\hline & \multicolumn{2}{|c|}{$\begin{array}{l}\text { Change in ICS Days-of-Supply } \\
\text { from } 2003 \text { to } 2004\end{array}$} & \multicolumn{3}{|c|}{$\begin{array}{c}\text { Change in ICS Days-of-Supply from } 2003 \text { to 2004: Restricted } \\
\text { vs. Unrestricted Coverage (Difference-in-difference) }\end{array}$} \\
\hline & $\begin{array}{l}\text { Restricted } \\
\text { Coverage }\end{array}$ & $\begin{array}{l}\text { Unrestricted } \\
\text { Coverage }\end{array}$ & $\begin{array}{l}\text { Restricted vs. } \\
\text { Unrestricted }\end{array}$ & $(95 \% \mathrm{Cl})$ & p-value \\
\hline $\begin{array}{l}\text { All Subjects } \\
(\mathrm{n}=1,802)\end{array}$ & -30.27 & $-|4.8|$ & -15.47 & $(-24.98,-5.95)$ & 0.001 \\
\hline $\begin{array}{l}\text { Lower-cost ICS Users in } 2003 \\
(n=1,140)\end{array}$ & -26.38 & -13.55 & -12.84 & $(-24.34,-1.33)$ & 0.029 \\
\hline $\begin{array}{l}\text { Continued using lower-cost ICS in } \\
2004(n=960)\end{array}$ & -13.08 & 0.63 & $-|3.7|$ & $(-25.52,-1.90)$ & 0.023 \\
\hline $\begin{array}{l}\text { Switched to higher-cost ICS in } \\
2004 \\
(n=25)\end{array}$ & -54.24 & 29.51 & -83.75 & $(-171.58,4.07)$ & 0.060 \\
\hline $\begin{array}{l}\text { Higher-cost ICS Users in } 2003 \\
(n=662)\end{array}$ & -37.40 & -15.60 & -21.80 & $(-38.46,-5.13)$ & 0.010 \\
\hline $\begin{array}{l}\text { Continued using higher-cost ICS in } \\
2004(n=354)\end{array}$ & -39.81 & -1.19 & -38.62 & $(-56.96,-20.28)$ & $<.001$ \\
\hline $\begin{array}{l}\text { Switched to lower-cost ICS in } 2004 \\
(n=2 I 2)\end{array}$ & 0.71 & -18.04 & 18.75 & $(-27.46,64.96)$ & 0.425 \\
\hline
\end{tabular}

Notes: Each row represents a separate OLS regression model. Among lower-cost ICS users in 2003, 155 subjects had no ICS drug use in 2004 , among higher-cost ICS users in 2003, 96 subjects had no ICS drug use in 2004. We calculated mean changes in ICS days-of-supply for each coverage group by using the lincom command in Stata 8.2 and the mean levels of the covariables. 
Table 5: Adjusted change in annual ICS days-of-supply for lower and higher-risk asthma patients: restricted vs. unrestricted coverage

\begin{tabular}{|c|c|c|c|c|c|c|c|}
\hline & \multicolumn{2}{|c|}{$\begin{array}{l}\text { Baseline ICS Days-of- } \\
\text { Supply (2003) }\end{array}$} & \multicolumn{2}{|c|}{$\begin{array}{l}\text { Change in ICS Days-of-Supply } \\
\text { from } 2003 \text { to } 2004\end{array}$} & \multicolumn{3}{|c|}{$\begin{array}{l}\text { Change in ICS Days-of-Supply from } 2003 \text { to } \\
\text { 2004: Restricted vs. Unrestricted Coverage } \\
\text { (Difference-in-difference) }\end{array}$} \\
\hline & $\begin{array}{l}\text { Restricted } \\
\text { Coverage }\end{array}$ & $\begin{array}{l}\text { Unrestricted } \\
\text { Coverage }\end{array}$ & $\begin{array}{l}\text { Restricted } \\
\text { Coverage }\end{array}$ & $\begin{array}{l}\text { Unrestricted } \\
\text { Coverage }\end{array}$ & $\begin{array}{l}\text { Restricted vs. } \\
\text { Unrestricted }\end{array}$ & $(95 \% \mathrm{Cl})$ & $\mathrm{P}$-value \\
\hline $\begin{array}{l}\text { Lower-risk asthma } \\
\text { patients }(n=1,584)\end{array}$ & 181.20 & 197.70 & -30.46 & -14.90 & -15.56 & $(-25.77,-5.34)$ & 0.003 \\
\hline $\begin{array}{l}\text { Higher-risk asthma } \\
\text { patients }(n=218)\end{array}$ & 192.79 & 227.58 & -28.97 & -14.00 & -14.97 & $(-41.38,11.44)$ & 0.265 \\
\hline
\end{tabular}

Notes: Each row represents a separate OLS regression model. We classified those with a high-risk asthma flag as higher-risk and those with no highrisk flag as lower-risk asthma patients (please see Table 3). We calculated mean changes in ICS days-of-supply for each coverage group by using the lincom command in Stata 8.2 and the mean levels of the covariables. The baseline ICS days-of-supply presents the unadjusted mean days-of-supply in each group in 2003.

essary to achieve a specific effect, may differ across different ICS types. Notably, fluticasone propionate (the primary higher-cost ICS in this study) appears to achieve similar improvements in lung function at half the dose of beclomethasone dipropionate (the lower-cost ICS) $[20,21]$. Thus, the higher-cost ICS drugs may offer simpler daily dosing regimens, such as requiring fewer administrations per day, compared with the lower-cost ICS, which might encourage better regimen adherence especially for patients prescribed a high ICS dose (i.e., patients with a more frequent dosing schedule) [22]. More work is needed to explore whether patients were aware of the availability of a lower-cost ICS and to examine other potential barriers to switching.

Poor adherence to ICS therapy has been demonstrated in other studies [4,23-28]. Two Canadian studies found that increases in drug cost-sharing were associated with decreases in ICS use in elderly patients and children $[29,30]$. To our knowledge, no studies have examined the impact of drug coverage restrictions on ICS use in Medicare populations. Our findings suggest that patients who lose coverage for their inhaled corticosteroids may reduce their levels ICS use. Of importance, this health system was able to provide a lower price on beclomethasone dipropionate, due to negotiated discounts, than is likely to be available in other settings. Therefore, our findings of decreases in ICS use due to generic-only coverage in this setting raise important questions about the potential for more pronounced effects in other settings where a lowercost ICS is not available. This highlights the importance of providing patients with a low-cost ICS option during uncovered periods, such as Part D coverage gaps, to encourage continued adherence to ICS therapy.

Because ours was a non-randomized study it is possible that differential changes in ICS use between the restricted and unrestricted groups are due to unmeasured differences. We were able to adjust for a large a number of socio-demographic and clinical characteristics, including a number of asthma severity measures. Identifying patients with persistent asthma based on administrative data is challenging; we examined other cohort definitions of varying restrictiveness (e.g., including patients with a secondary inpatient diagnosis of asthma) and found similar results across these definitions. ICS use was measured using pharmacy data. These data do not capture whether patients actually took dispensed medications or took them correctly; we also did not assess the clinical effects of changes in ICS use. The pharmacy data do not include drugs dispensed outside of KPNC; however, patients had a financial incentive to purchase their medications within KPNC because of favorable in-system prices throughout the study period. As a result, in telephone interviews, members report rarely going outside of the system to obtain medications or other services [31]. Lastly, this integrated delivery system may have an enhanced ability to monitor care and control drug costs, which may minimize potential harms due to increases in cost-sharing.

\section{Conclusion}

This study highlights the importance of offering a lowcost option within the ICS drug class, particularly during uncovered periods, such as during the Medicare Part D coverage gap. Insurers may also consider maintaining coverage for ICS drugs during otherwise uncovered periods for patients with a clinical need for these drugs. Additional work is needed to understand patient responses to drug cost-sharing, especially for patients who did not switch to the lower-cost option yet reduced ICS use, as well as the clinical effects of restricted drug coverage policies.

\section{Abbreviations}

CI: confidence interval; COPD: chronic obstructive pulmonary disorder; ED: emergency department; ICS: inhaled corticosteroids; KPNC: Kaiser Permanente-Northern California; MA: Medicare Advantage; OR: odds ratio. 


\section{Competing interests}

The authors declare that they have no competing interests.

\section{Authors' contributions}

VF made substantial contributions to the study's conception and design, acquisition of data, analysis and interpretation of data, drafted the manuscript, and revised the manuscript critically for important intellectual content. IBT made substantial contributions to the study's design, analysis and interpretation of the data, and revised the manuscript critically for important intellectual content. RB made substantial contributions to the study's design, analysis and interpretation of the data, and revised the manuscript critically for important intellectual content. JPN made substantial contributions to the study's design, analysis and interpretation of the data, and revised the manuscript critically for important intellectual content. JH made substantial contributions to the study's conception and design, acquisition of data, analysis and interpretation of the data, and revised the manuscript critically for important intellectual content. All authors read and approved the final manuscript.

\section{Acknowledgements}

The Agency for Healthcare Research and Quality (AHRQ), the National Institute on Aging (NIA), the Alfred P. Sloan Foundation, and the University of California at Berkeley, School of Public Health, Grossman Doctoral Research Award provided funding for the study. Neither funding agencies nor the health system had any role in the design, analysis, interpretation, or decision to submit this manuscript for publication. The authors have no other relevant financial disclosures.

\section{References}

I. Medicare Payment Advisory Commission (MedPAC): Report to Congress: Medicare Payment Policy. Washington D.C. ; 2007.

2. Global Initiative for Asthma (GINA): Global Strategy for Asthma Management and Prevention. NIH Publication No 02-3659 2004

3. National Center for Health Statistics: Asthma data on demand. [http://www.cdc.gov/nchs/health data for all ages.htm].

4. Apter AJ, Boston RC, George M, Norfleet AL, Tenhave T, Coyne JC Birck K, Reisine ST, Cucchiara AJ, Feldman HI: Modifiable barriers to adherence to inhaled steroids among adults with asthma: it's not just black and white. I Allergy Clin Immunol 2003, I I I(6): | 2 |9-| 226.

5. Barnes PJ, Pedersen S, Busse WW: Efficacy and safety of inhaled corticosteroids. New developments. Am J Respir Crit Care Med I998, I57(3 Pt 2):SI-53.

6. Williams LK, Pladevall M, Xi H, Peterson EL, Joseph C, Lafata JE, Ownby DR, Johnson CC: Relationship between adherence to inhaled corticosteroids and poor outcomes among adults with asthma. Journal of Allergy and Clinical Immunology 2004, I | 4(6): | 288-1293.

7. McKnight J, Scott A, Menzies D, Bourbeau J, Blais L, Lemiere C: A cohort study showed that health insurance databases were accurate to distinguish chronic obstructive pulmonary disease from asthma and classify disease severity. J Clin Epidemiol 2005, 58(2):206-208.

8. Krieger N, Gordon D: Use of Census-Based Aggregate Variables to Proxy for Socioeconomic Group: Evidence from National Samples. Am J Epidemiol 1999, 150:892-896.

9. Subramanian SV, Chen JT, Rehkopf DH, Waterman PD, Krieger N Comparing individual- and area-based socioeconomic measures for the surveillance of health disparities: a multileve analysis of Massachusetts births, 1989-I99I. Am J Epi 2006, I 64(9):823-834.
I0. Pope GC, Kautter J, Ellis RP, Ash AS, Ayanian JZ, lezzoni LI, Ingber MJ, Levy JM, Robst J: Risk adjustment of Medicare capitation payments using the CMS-HCC model. Health Care Financing Review 2004, 25(4): || $|9-| 4 \mid$.

II. Rosenbaum PR, Rubin DB: The Central Role of the Propensity Score in Observational Studies for Causal Effects. Biometrika I 983, 70(I):4I-55

12. Rubin DB: Estimating Causal Effects from Large Data Sets Using Propensity Scores. Ann Intern Med 1997. I 27(5_Part_2):757-763.

13. Farber HJ, Capra AM, Finkelstein JA, Lozano P, Quesenberry CP, Jensvold NG, Chi FW, Lieu TA: Misunderstanding of asthma controller medications: association with nonadherence. J Asthma 2003, 40(I): 17-25.

14. Suissa S, Ernst P, Benayoun S, Baltzan M, Cai B: Low-dose inhaled corticosteroids and the prevention of death from asthma. $N$ Engl J Med 2000, 343(5):332-336.

15. Armstrong EP, Malone DC: Fluticasone is associated with lower asthma-related costs than leukotriene modifiers in a realworld analysis. Pharmacotherapy 2002, 22(9): I I I7- I I 23.

16. Halpern MT, Khan ZM, Stanford RH, Spayde KM, Golubiewski M: Asthma: resource use and costs for inhaled corticosteroid vs leukotriene modifier treatment--a meta-analysis. J Fam Pract 2003, 52(5):382-389.

17. Lamb HM, Culy CR, Faulds D: Inhaled fluticasone propionate. A pharmacoeconomic review of its use in the management of asthma. Pharmacoeconomics 2000, I 8(5):487-510.

18. Sullivan SD, Buxton M, Andersson LF, Lamm C], Liljas B, Chen YZ, Pauwels RA, Weiss KB: Cost-effectiveness analysis of early intervention with budesonide in mild persistent asthma. J Allergy Clin Immunol 2003, I I 2(6): I 229- I 236.

19. Volmer T, Kielhorn A, Weber HH, Wiessmann KJ: Cost effectiveness of fluticasone propionate and flunisolide in the treatment of corticosteroid-naive patients with moderate asthma. Pharmacoeconomics 1999, I6(5 Pt 2):525-531.

20. Adams N, Bestall JM, Lasserson TJ, Jones PW: Inhaled fluticasone versus inhaled beclomethasone or inhaled budesonide for chronic asthma in adults and children. Cochrane Database Syst Rev 2005:CD002310.

21. Barnes NC, Hallett C, Harris TA: Clinical experience with fluticasone propionate in asthma: a meta-analysis of efficacy and systemic activity compared with budesonide and beclomethasone dipropionate at half the microgram dose or less. Respir Med 1998, 92(I):95-104.

22. Mann M, Eliasson O, Patel K, ZuWallack RL: A comparison of the effects of bid and qid dosing on compliance with inhaled flunisolide. Chest 1992, I 0 I (2):496-499.

23. Shrank WH, Hoang T, Ettner SL, Glassman PA, Nair K, DeLapp D, Dirstine J, Avorn J, Asch SM: The implications of choice: prescribing generic or preferred pharmaceuticals improves medication adherence for chronic conditions. Arch Intern Med 2006, I 66(3):332-337.

24. Bender BG, Pedan A, Varasteh LT: Adherence and persistence with fluticasone propionate/salmeterol combination therapy. J Allergy Clin Immunol 2006, I I 8(4):899-904.

25. Cochrane MG, Bala MV, Downs KE, Mauskopf J, Ben-Joseph RH Inhaled Corticosteroids for Asthma Therapy: Patient Compliance, Devices, and Inhalation Technique. Chest 2000 , I I 7(2):542-550.

26. Horne R: Compliance, Adherence, and Concordance: Implications for Asthma Treatment. Chest 2006, I30(I suppl):65S-72.

27. De Smet BD, Erickson SR, Kirking DM: Self-reported adherence in patients with asthma. Ann Pharmacother 2006, 40(3):4|4-420.

28. Kelloway JS, Wyatt R, DeMarco J, Adlis S: Effect of salmeterol on patients' adherence to their prescribed refills for inhaled corticosteroids. Ann Allergy Asthma Immunol 2000, 84(3):324-328.

29. Dormuth CR, Glynn RJ, Neumann P, Maclure M, Brookhart AM, Schneeweiss S: Impact of two sequential drug cost-sharing policies on the use of inhaled medications in older patients with chronic obstructive pulmonary disease or asthma. Clin Ther 2006, 28(6):964-78; discussion 962-3.

30. Kozyrskyj AL, Mustard CA, Cheang MS, Simons FER: Income-based drug benefit policy: impact on receipt of inhaled corticosteroid prescriptions by Manitoba children with asthma. Canadian Medical Association Journal 200I, 165(7):897-902. 
31. Reed M, Fung V, Brand R, Fireman B, Newhouse JP, Selby JV, Hsu J: Care-Seeking Behavior in Response to Emergency Department Copayments. Med Care 2005, 43(8):810-816.

\section{Pre-publication history}

The pre-publication history for this paper can be accessed here:

http://www.biomedcentral.com/1472-6963/8/151/pre

pub

Publish with Bio Med Central and every scientist can read your work free of charge

"BioMed Central will be the most significant development for disseminating the results of biomedical research in our lifetime. " Sir Paul Nurse, Cancer Research UK

Your research papers will be:

- available free of charge to the entire biomedical community

- peer reviewed and published immediately upon acceptance

- cited in PubMed and archived on PubMed Central

- yours - you keep the copyright

Submit your manuscript here:

http://www.biomedcentral.com/info/publishing_adv.asp
BioMedcentral 